3-1-1986

\title{
Communication tendencies of senior dental students.
}

David G. Dunning

University of Nebraska Medical Center, ddunning@unmc.edu

Brian M. Lange

University of Nebraska Medical Center, blange@unmc.edu

Tell us how you used this information in this short survey.

Follow this and additional works at: https://digitalcommons.unmc.edu/cod_articles

Part of the Dentistry Commons

\section{Recommended Citation}

Dunning, David G. and Lange, Brian M., "Communication tendencies of senior dental students." (1986). Journal Articles: College of Dentistry. 14.

https://digitalcommons.unmc.edu/cod_articles/14

This Article is brought to you for free and open access by the College of Dentistry at DigitalCommons@UNMC. It has been accepted for inclusion in Journal Articles: College of Dentistry by an authorized administrator of DigitalCommons@UNMC.For more information, please contact digitalcommons@unmc.edu. 


\title{
Communication Tendencies of Senior Dental Students
}

\author{
David G. Dunning, M.A.; Brian M. Lange, Ph.D.
}

\begin{abstract}
Although the importance of dentist-patient communication is generally recognized, the dental literature does not specify what interpersonal behaviors can be used as a basis for evaluating dental students' communication skills. A set of behaviors based on clinical observations is described, and an evaluation of 25 senior students' behavioral skills is presented. Students often did not: (1) spend much time orienting patients before beginning treatment; (2) update medical histories; (3) ask patients if they had any questions before beginning treatment; (4) explain the operation and use of equipment; (5) forewarn patients about uncomfortable procedures; (6) attend to signs of patient discomfort; (7) reinforce praiseworthy patient behavior; (8) caution patients about numbness, chewing, and sensitivity; (9) thank patients for their time; and (10) use leading/motivating questions. There is a need to provide students with systematic feedback on their interpersonal behaviors.
\end{abstract}

B oth practitioners and researchers in dentistry recognize the importance of what an earlier generation called "bedside" or "chairside" manners. Courses in the behavioral sciences, patient management, and interpersonal skills are now the rule rather than the exception. The devotion of an entire issue of the Journal of Dental Education in 1983 to interpersonal skills demonstrates perhaps more convincingly than anything else the fact that this topic is critically important in dentistry. ${ }^{1}$

Despite all the attention given to interpersonal communication, a list of specific interpersonal behaviors with which to evaluate student skills has yet to appear in the literature. While some reports offer suggestions, ${ }^{2-5}$ currently there is neither an adequate behavioral foundation for feedback nor a baseline description of normative dental student interpersonal behavior in the clinic. Because interpersonal communication with patients is simultaneously problematic for the participants and pivotal to patient satisfaction and compliance, $^{6-7}$ the need for the development of measurement

Mr. Dunning is instructor, and Dr. Lange is assistant professor, both at the College of Dentistry, University of Nebraska, Medical Center, Lincoln, NE 68583-0740. and feedback strategies is obvious. This paper begins that process by describing baseline data obtained in observations of student interpersonal behavior.

\section{Key Interpersonal Behaviors}

Twenty-seven interpersonal behaviors were identified and described through 30 hours of unstructured clinical observations of restorative appointments, and from consideration of studies of physician-patient conversation. ${ }^{8-10}$ The behaviors, which are specific to stages of a treatment appointment, are listed in Table 1. The behaviors listed in Parts $\mathrm{A}$ and $\mathrm{C}$ are evaluated respectively toward the beginning and end of the appointment on a simple yes/no basis. The behaviors listed in Part B are evaluated more rigorously in that they require ratings according to qualitative degrees of performance. For example, the evaluation options developed for item 15 are presented as:

When the patient verbally or nonverbally expressed signs of discomfort, the dental student:

(a) questioned the patient to identify the feeling or sensation and comforted the patient with a touch on the shoulder or arm,

(b) questioned the patient to identify the feeling or sensation,

(c) identified or acknowledged the feeling or sensation without asking the patient what he or she was experiencing,

(d) was unaware of the nonverbal cue,

(e) ignored the verbal or nonverbal cue.

\section{Baseline Data}

Baseline data were obtained by observing 25 appointments involving 25 members of the 1985 graduating class and 25 patients. The observations were made by two investigators between February and May of 1985 in the Senior General Practice Program at the College of Dentistry, University of Nebraska Medical Center, ${ }^{\text {II }}$ These were not randomly selected appointments in that observations had to be scheduled around other responsibilities. Also, preference was given to shorter appointments - all but six were less than two hours. Students were instructed to delay any conversation about the scheduled treatment until the patient was in 
Table 1. Desirable Student Behavior

Part A: First Few Minutes of Appointment

1. Assisting the patient with belongings.

2. Referring to the patient by name.

3. Explaining how the appointment fits into the overall treatment plan.

4. Explaining the day's treatment rather than simply naming it.

5. Updating the medical history.

6. Negotiating a specific signal so that the patient can request momentary cessation of treatment.

7. Asking the patient about feelings or difficulties associated with the last appointment.

8. Asking the patient if there are any questions before beginning treatment.

\section{Part B: During Treatment}

9. Explaining/demonstrating equipment.

10. Informing the patient about the progress of the day's treatment.

11. Forewarning the patient about uncomfortable procedures.

12. Soliciting/answering patient questions.

13. Taking leave of the patient.

14. Introducing instructors and explaining what they will do/ did.

15. Recognizing/addressing signs of patient discomfort.

16. Praising/complimenting patient behaviors.

17. Asking the patient how he or she is doing.

\section{Part C: Last Few Minutes of Appointment}

18. Asking the patient if there are any questions.

19. Instructing the patient about numbness and chewing precautions.

20. Allowing the patient to sit upright for a sufficient length of time before dismissal.

21. Reminding the patient about the next planned treatment.

22. Making an appointment for the next treatment.

23. Assisting the patient with belongings.

24. Thanking the patient for time, cooperation, etc.

25. Encouraging the patient to call if dental-related problems arise.

26. Escorting the patient to the lobby.

27. Leaving the patient with a motivating/leading question such as, "See you a week from Thursday, OK?"

the cubicle. Following the appointments, individual feedback conferences approximately 30 minutes long were held with students to discuss skill strengths and weaknesses.

Three of the first nine appointments were videotaped so that the investigators could determine the reliability of their observations. Using a small sample of data to assess interrater reliability with behavioral indices and then incorporating those data in the results is an accepted practice in communication studies. ${ }^{12-13}$ The two in- vestigators agreed on 95 percent of the behaviors evaluated across the three appointments. Disagreements were resolved by reviewing the videotapes and by discussion. Most of the disagreements concerned the evaluation of statements that informed patients of treatment progress (Part B, item 10 - e.g., overall procedural steps versus substeps), and the evaluation of question-answer sequences as groups versus individual pairs (Part B, item 12).

Of the 25 appointments observed, ten involved amalgams; five, composites; two, crown preps; three, crown seatings; and five, bridge or denture impressions and adjustments. Eleven of the 25 patients ( 45 percent) previously had had the same treatment performed by the same student. The average length of time since the previous appointment was 22 days, ranging from 2 to 62. Patients' ages ranged from 20-75, with 15 being females and 10 males. The mean appointment length was 102 minutes. On average, patients had seen their dental students eight times previously, with the first two appointments typically used for history-taking, $x$ rays, and treatment planning.

Students briefly explained the overall treatment plan and how the days' treatment fit in it only 17 percent of appropriate times. Just 52 percent of the students explained the day's treatment (that is, reviewed the steps of the treatment) rather than just naming it. Students did not attempt to update patients' medical histories in 82 percent of the appointments where this was appropriate (no update for six months or need for continuous monitoring). Lastly, only eight percent of the students asked if their patients had any questions before beginning treatment. The purpose in doing so is of course to see if the patient is informed, or has any concerns or anxieties.

Whereas students did a fairly thorough job of informing patients about the progress of the day's treatment, they proceeded without explaining the use of equipment 65 percent of the time. Students forewarned patients about potentially uncomfortable procedures directly 36 percent of the time, and failed to mention discomfort at all 46 percent of the time. While students answered patient questions in specific, understandable terms 70 percent of the time, they solicited questions from patients at a rate of only 5 percent. On average, in 102 minutes, patients asked just over three questions, paralleling the average number of questions in physician appointments and suggesting that patient-initiated questions are probably just as uncommon in dentistry as they are in physician-patient communication. ${ }^{10}$ Students ignored signs of discomfort (such as clenched eyebrows, shuffling feet, white knuckles, and moans) 19 percent of the time and were unaware of the same in 23 percent of the cases. Not one of the 25 students praised patients for excellence in home care; furthermore, students complimented patients for cooperative behavior during treatment only 1.24 times on average per appointment, or once every 82 minutes. Students 
checked on the welfare of patients by asking how they were doing once every 27 minutes on average.

Only one student asked if the patient had any questions at the end of treatment. Of those appointments involving anesthesia, students did not instruct patients about chewing precautions and numbness in 42 percent of the cases. Finally, students thanked patients for coming in for appointments 50 percent of the time and left patients with motivating questions in 38 percent of the appointments where appropriate.

\section{Discussion}

It should be noted that students did not study the behaviors listed in Table 1 prior to being observed. However, the students evaluated were senior dental students who had successfully completed three credit hours of core didactic courses in patient management: a two-credit-hour course on human behavior that incorporated material on perception, communication, pain control, and management of normal patients; and a one-credit-hour course on special patients that applied material learned in the human behavior analysis course. Moreover, these students were in the last four months of clinical training and knew that their interpersonal skills were being observed.

The portrait painted by the results is that of underinformed patients, risky situations, and missed opportunities. Students are lax in obtaining updated medical histories, and spend little time orienting their patients to treatment they are about to receive or to the overall treatment plan. Also, students tend not to check with their patients to see if they have any questions or concerns.

The majority of students typically proceeded without explaining the use of equipment to their patients. While some equipment may not have required an explanation, depending on the patient's experience and history, the treatment being provided was new to 55 percent of the patients, "new" meaning that the students had not previously provided the treatment for those patients. The amount of forewarning and attention students paid to their patients also was disappointing considering that drilling, injecting, and blowing air into carious lesions are among the most frequent and most fearful dental procedures. ${ }^{14}$

Among the most troubling of all the findings is students' frequent lack of response to patient signs of discomfort. Even though students lacked the support of assistants, such inattention to anxiety and pain related indicators is a far cry from empathy and understanding as suggested by the Curriculum Guidelines for Behavioral Sciences. ${ }^{15}$ Not only did students tend to be unresponsive to their patients during treatment, they also failed to reinforce appropriate patient behavior (good oral hygiene, or cooperation during treatment) and neglected to motivate patients through the use of simple "thanks" and leading questions (such as, "I'll see you a week from Monday, then, right?").

The results of these observations provide support for the suggestion that "a technology for improving communication with and management of patient behavior should be a part of a dental student's core knowledge. ${ }^{16}$ The notion of a "technology" being imparted to dental students gives rise to a number of concerns. The Curriculum Guidelines ${ }^{15}$ address the concern of what should be taught. They identify the behavioral skills that should be expected of a dental student, including communication skills, interviewing skills, and behavioral management of patients. The proceedings of the national conference on applied behavioral sciences ${ }^{1}$ include suggestions on where and how interpersonal skills should be taught, including the suggestion that interpersonal skills are taught most effectively in a learning environment that features practice, guided observation, and systematic feedback.

Absent from the literature are specific communication behaviors upon which to evaluate student interpersonal skills and to provide feedback to students on the acquisition of skills. Without establishing a baseline for students and subsequently checking their progress, educators cannot expect students to acquire communication competence. The absence of specific communication behaviors in the dental literature may be due in part to the belief that suggesting or mandating one set of specific behaviors for competency would be inappropriate. Establishing a minimum number of verbal statements per student may be inappropriate: identifying and evaluating critical behaviors that students need to model consciously in the communication process is not inappropriate. At the University of Nebraska, future students will receive more instruction in communication theory and practice, and the interpersonal behaviors will be modeled using videotaped examples. Senior students will be videotaped during two restorative appointments, with behaviors evaluated and then discussed by the student and instructor in two conferences. Students whose skills remain below acceptable levels will be videotaped a third time.

\section{REFERENCES}

1. J. Dent. Educ. 47(2), 1983.

2. Hollifield, G., C. T. Rousell, A. J. Backrach, E. G. Pattishall. A Method of Evaluating Student-Patient Interaction. J. Med. Educ, 32(12):853-7, 1957.

3. Maguire, P., P. Roe, D. Goldberg, S. Jones, C. Hyde, T. O'Dowd. The Value of Feedback in Teaching Interviewing Skills to Medical Students. Psychological Medicine. 8(3):695-704, 1978.

4. Johnson, D. C., D. B. Schubot, D. A. Nash. A Criterion-Referenced Self-Instructional Format for Teaching Child Management Skills in the Clinic. J. Dent. Educ. 47(2):113-14, 1983.

5. Jackson, E. Convergent Evidence for the Effectiveness of Interpersonal Skill Training for Dental Students. I. Dent. Educ. 42(8):517-23, 1978.

6. Furnham, A. Social Skills and Dentistry. Brit. Dent. J. 154(12):4048, 1983.

7. Ben-Sira, Z. The Function of the Professional's Affective Behavior in Client Satisfaction-A Revised Approach to Action Theory. I. Health Soc. Behav. 17(2):3-17, 1976. 
8. Fisher, S., and A. D. Todd. The Social Organization of Doctor-Patient Communication. Washington, D.C.: Center for Applied Linguistics, 1983.

9. Frankel, R. M. Talking in Interviews: A Dispreference for PatientInitiated Questions in Physician-Patient Encounters. In Interactional Competence. G. Psathas (Ed.) New York: Irvington, in press.

10. West, C. Routine Complications: Trouble with Talk between Doctors and Patients. Bloomington: Indiana University Press, 1984, 71-96.

11. Jones, D. A. Quality-You've Got to be Taught. Journal of Dental Practice Administration. 1(4):159-61, 1984.

12. Downs, C. W., and C. Conrad. Effective Subordinancy. J. Bus. Commun. 19(2):27-37, 1982.
13. Brown, M. H. That Reminds Me of a Story: Speech Action in Organizational Socialization. West. J. Speech Commun. 49(1):27-42, 1985.

14. Pardon, R. Managing the Anxious Patient. Dentalpractice. 1(2):68B-D, 1980.

15. Curriculum Guidelines for Behavioral Sciences in Dentistry. $J$. Dent. Educ. 48(9):520-26, 1984.

16. Gershen, J. A. Use of Experimental Techniques in Interpersonal Skills Training. J. Dent. Educ. 47(2):72-75, 1983. 